\title{
Measurement of Dynamic Dough Density and Effect of Surfactants and Flour Type on Aeration During Mixing and Gas Retention During Proofing
}

\author{
Grant M Campbell, ${ }^{1,2}$ Roberto Herrero-Sanchez, ${ }^{1}$ Roman Payo-Rodriguez, ${ }^{1}$ and Maria Luisa Merchan ${ }^{1}$
}

\section{ABSTRACT}

Cereal Chem. 78(3):272-277

\begin{abstract}
A new method for measuring dough densities is presented, based on weighing small dough samples in air and immersed in xylene. The method can be used to evaluate the air content of low-density doughs and to follow the changing density of a proofing dough sample. The method is applied to evaluate the effect of flour strength and surfactant addition on dough aeration and subsequent proofing. Doughs were mixed in a highspeed mixer from two flours, a strong breadmaking flour and a weak flour. Surfactants sodium stearoyl lactylate (SSL) and diacetyl tartrate esters of monoglyceride (DATEM) were added at three levels, and the air
\end{abstract}

content, proofing dynamics, and baked loaf quality were evaluated. The air content of dough was proportional to headspace pressure in the mixer, while the strong flour occluded less air than the weak flour. Surfactants greatly improved the volume of baked loaves but appeared to have no significant effect on air incorporation during mixing. The addition of surfactants appeared to increase the rate of growth of the dough piece during proofing, possibly due to increased bubble breakup during mixing or to increased rates of mass transfer of $\mathrm{CO}_{2}$ into bubbles during proofing.
Creating the aerated structure of bread starts with the bubble structure developed in the mixer. In modern no-time processes such as the Chorleywood Bread Process (CBP), the bubbles incorporated during mixing have a direct effect on baked loaf structure (Chamberlain et al 1962; Campbell and Shah 1999; Cauvain et al 1999). Aeration during mixing can be characterized by measuring the air content of the dough and the bubble size distribution. Measuring the latter is difficult, requiring taking thin slices of frozen dough, measuring the distribution of hole sizes appearing on these slices, and reconstructing the bubble size distribution (Campbell et al 1991, 1999; Whitworth and Alava 1999). Measuring dough density is easier, indicating only the gross air content of the dough and requiring care in interpretation (Campbell et al 1993). However, existing methods of measuring dough density are relatively inconvenient. A new method is presented here which is more convenient and which also allows monitoring of the change in density of a proofing (proving in some countries) dough piece.

Flour type and ingredients strongly affect baked loaf quality. Doughs from strong flours incorporate less air during mixing than doughs from weak flours and give larger loaf volumes, finer crumb structures, or both (Baker and Mize 1946; Chamberlain et al 1970; He and Hoseney 1991; Campbell et al 1993; Hayman et al 1998). Surfactants such as diacetyl tartrate esters of monoglyceride (DATEM) and sodium stearoyl-2-lactylate (SSL) are added to bread formulations to increase loaf fineness, softness, and volume; to strengthen doughs and improve mixing tolerance; and to delay crumb staling (Knightly 1981, 1988; Stauffer 1999). Surfactants (including naturally present proteins and polar lipids) are versatile molecules that will congregate at interfaces of hydrophobic and hydrophilic phases. Within doughs there are many such interfaces, including the air-water interface of bubbles and the fat-water interface of shortenings. Surfactants also interact with the large protein and starch molecules that compose the bulk of the viscoelastic liquid phase of dough and solid phase of bread. Surfactants in bread systems have been widely studied and are believed to be active in several areas.

Surfactants interact with proteins and starch in the dough, countering the adverse effects of foreign protein on loaf volume (Knightly 1988), maintaining frozen doughs (Inoue et al 1995), and retarding bread staling (Krog 1981; Bloksma and Bushuk 1988; Knightly

${ }^{1}$ Satake Centre for Grain Process Engineering, Dept. of Chemical Engineering, UMIST, PO Box 88, Manchester, M60 1QD, UK.

${ }^{2}$ Corresponding author. Phone: +44 (0)161 200 4472; Fax +44 (0)161 200 4399; E-mail: g.campbell@umist.ac.uk

Publication no. C-2001-0412-04R.

(C) 2001 American Association of Cereal Chemists, Inc.
1988; Xu et al 1992; Roach and Hoseney 1995; Armero and Collar 1996a,b; Keetels et al 1996; Collar et al 1998; Stauffer 1999).

Dough conditioners or strengtheners are generally anionic surfactants that promote protein aggregation, modifying the mixing properties of doughs to obtain higher or later arriving consistency peaks and increased tolerance to mixing time and rate $\mathrm{Tu}$ and Tsen 1978; Tsen and Weber 1981; Knightly 1981, 1988; Stampfli et al 1996; Kenny et al 1999; Kohler and Grosch 1999; Stauffer 1999)

Surfactants may affect proofing times. Knightly $(1981,1988)$ noted that dough conditioning surfactants improve gas retention and thus proofing rate. Tsen and Weber (1981) reported that some surfactants (including SSL and DATEM) reduced proof times and promoted gas production, whereas other surfactants had the opposite effect. Those surfactants that reduced proof times also increased farinograph development time and stability. Surfactants increase loaf fineness and volume (Junge and Hoseney 1981; Junge et al 1981; Bruinsma and Finney 1984; Moore and Hoseney 1986; Knightly 1981, 1988; Lindsay 1996; Kenny et al 1999; Kohler and Grosch 1999; Stauffer 1999).

Several mechanisms have been proposed to explain the effects of surfactants on loaf fineness and volume. First, that surfactants aid the breakup of bubbles in the mixer; these smaller bubbles therefore result in more and smaller gas cells in the baked loaf. Second, that, alternatively or in addition, surfactants retard bubble coalescence during proofing and baking by reducing the surface tension and thereby the thermodynamic benefit of coalescence, or by strengthening the liquid film between bubbles.

The first of these hypotheses notes that surfactants lower the surface tension at the interface of air bubbles. Generally, within aerated systems, lowering of surface tension aids bubble breakup; this mechanism could contribute to fineness of the crumb structure delivered in the baked loaf by the use of surfactants. Junge et al (1981) took photomicrographs of aerated dough structure in doughs mixed in a mixograph with and without surfactants, and reported that surfactants that improved crumb fineness also appeared to produce smaller bubbles in the dough. Surfactant addition also altered the rate of dough development and air incorporation in the mixograph, although the amount of air occluded (as indicated by dough density) was not changed by the addition of surfactants.

Another feature of surfactants is that, by lowering the surface tension at interfaces, they reduce the thermodynamic driving force for bubble coalescence. It is therefore likely that surfactants in bread doughs reduce bubble coalescence during the final stages of proofing and early stages of baking, which would also produce a finer structure in the baked loaf. Gan et al (1995) described the liquid film hypothesis as a framework in which to understand the relative contributions of gluten viscoelasticity and surface action 
of indigenous and added emulsifiers. In this framework, toward the end of proofing and during the early stages of baking, the gluten network responsible for the gas retention capabilities of wheat doughs develops discontinuities between adjacent bubbles. However the bubbles do not immediately coalesce because there remains a thin, fragile liquid film stabilized by surfactant material. This liquid film contributes a slight additional stability to the bubbles, giving an improvement in crumb fineness and loaf volume by delaying bubble coalescence and loss of gas. Addition of surfactants is likely to have at least part of its effect here, irrespective of any effects on bubble breakup in the mixer.

The air content of the dough from the mixer depends on the balance of entrainment and disentrainment of air during mixing (Campbell and Shah 1999). The latter appears to depend on the instantaneous air content of the dough and is likely to depend on the bubble size distribution in the dough. If bubble breakup during mixing is affected by surfactant addition, it might be expected to affect the rate of disentrainment of air during mixing and, hence, the balance with entrainment and the equilibrium air content.

After mixing, bubbles are inflated with carbon dioxide gas produced by yeast and dissolved in the liquid phase of the dough. The rate of diffusion of $\mathrm{CO}_{2}$ into bubbles depends on their size and number. Again, if surfactants affect bubble breakup during mixing, this might be expected to affect the balance between $\mathrm{CO}_{2}$ dissolution in the liquid phase and evaporation into bubbles and, hence, the observed rate of growth of the dough piece during proofing. Equally, the addition of surfactants might be expected to lower the partial pressure of $\mathrm{CO}_{2}$ in bubbles, increasing the concentration driving force for mass transfer, irrespective of any effects on bubble size in the mixer.

This article presents a new, more convenient method for measuring dough density after mixing and following the rate of dough piece expansion during proofing. The method is demonstrated by applying it to study the effect of flour type and surfactant addition on aeration of the dough during mixing and bubble growth during proofing. Baked loaves are examined to confirm the beneficial effect of surfactant addition on bread quality.

\section{MATERIALS AND METHODS}

\section{Dough Mixer and Formulation}

Doughs were mixed in a scaled-down version of an industrial Tweedy mixer, designed to mix doughs based on $\approx 1 \mathrm{lb}(454 \mathrm{~g}$ ) of flour. The mixer is connected independently to vacuum and compressed-air lines, allowing mixing at pressures above or below atmospheric, and allowing mixer headspace pressure to be changed midway through mixing if required. The mixer has a bowl diameter and depth of 135 and $126 \mathrm{~mm}$, respectively. The variable-speed mixing plate is bottom-mounted and has an octagonal base $90 \mathrm{~mm}$ in width and a shaft $60 \mathrm{~mm}$ in height. In these trials, the mixer was operated at a speed of $747 \mathrm{rpm}$ unloaded, reducing to $733 \mathrm{rpm}$ under load, rotating counterclockwise when viewed from above. Doughs were mixed for $3 \mathrm{~min}$ to a final dough temperature of $30 \pm 1^{\circ} \mathrm{C}$, achieved by adjusting the initial water temperature. Doughs were

TABLE I

Formula for Doughs Mixed in a Tweedy-type Mixer ${ }^{a}$

\begin{tabular}{lc}
\hline Ingredient $^{\mathbf{b}}$ & \%, flour weight basis \\
\hline Flour (strong or weak) & 100 \\
Water (distilled) & 60 \\
Yeast & 2.3 \\
Salt & 1.8 \\
Improver (Diamond) & 1.1 \\
Surfactant (DATEM or SSL) & $0,0.4,0.7$ \\
\hline
\end{tabular}

${ }^{a}$ Doughs were based on $400 \mathrm{~g}$ of flour.

b Yeast was omitted from doughs if not proofed; improver was surfactant and hemicellulose free; DATEM = diacetyl tartrate esters of monoglyceride; and SSL = sodium stearoyl lactylate. mixed at different headspace pressures ranging from 2 (high vacuum) to $30^{\prime \prime} \mathrm{Hg}$ abs (atmospheric pressure).

Doughs were prepared by mixing wheat flour, salt, water, yeast, and dough improver according to the formula given in Table I. Flour type (strong and weak) and improver type and level were varied. Strong additive-free breadmaking flour was obtained from Rank Hovis, Trafford Park, Manchester, UK. Weak flour was prepared by milling Riband wheat (a soft cultivar, 8.8\% protein, from the 1997 UK harvest, grown in the Humberside region) using laboratory Bühler milling. Doughs were based on $400 \mathrm{~g}$ of flour. The yeast used was Tesco Easy Blend Dried Yeast (Tesco Stores Ltd., Cheshunt, UK), containing dried yeast and sorbitan monostearate. Yeast was omitted from doughs except those used to follow growth of the dough piece during proofing or those from which loaves were baked. Free-running table salt was also obtained from Tesco. Commercial improvers were obtained from Arkady Craigmillar (Trafford Park, Manchester, UK). Surfactant- and hemicellulose-free Diamond (containing full-fat soy flour, dextrose, vegetable oil, and flour treatment agent E300 [ascorbic acid]) was used. To this was added DATEM (E472e in the European Union, US Code of Food Regulations Reference 182.4101) and SSL (E481, 172.846) at levels of 0, 0.4, and $0.7 \%$, flour weight basis.

\section{Measurement of Dough Density and Calculation of Air Content}

Dough densities were measured to evaluate the amount of air incorporated into the dough. Small dough samples $(\approx 10 \mathrm{~g})$ were weighed in air to $0.1 \mathrm{mg}$ using a Precisa 125A balance (Precisa Balances Ltd., UK), then immersed in a liquid of known density using a double-cup system and weighed again. From the difference in weights, the density was calculated using

$$
\rho=\frac{m_{\text {air }}}{m_{\text {air }}-m_{\text {liquid }}} \rho_{l}
$$

where $\rho$ is the dough density; $m_{\text {air }}$ and $m_{\text {liquid }}$ the weight of the dough in air and liquid, respectively; and $\rho_{1}$ the density of the liquid.

The liquid used was xylene $\left(\mathrm{C}_{6} \mathrm{H}_{4}\left(\mathrm{CH}_{3}\right)_{2}\right.$, mixed isomers, Fisher Scientific, Loughborough, UK), which has a density of $0.86 \mathrm{~g} \mathrm{~cm}^{-3}$ at $30^{\circ} \mathrm{C}$, and is nonwetting and nondissolving of the dough. The temperature of the xylene was maintained using a jacketed beaker through which water was recirculated from a temperature-controlled water bath. The temperature was maintained at $30^{\circ} \mathrm{C}$ for static measurements and at $40^{\circ} \mathrm{C}$ (to mimic proofing temperatures) for dynamic measurements. For safety, the system was operated in a fume cupboard. The double cup density meter and the temperature control

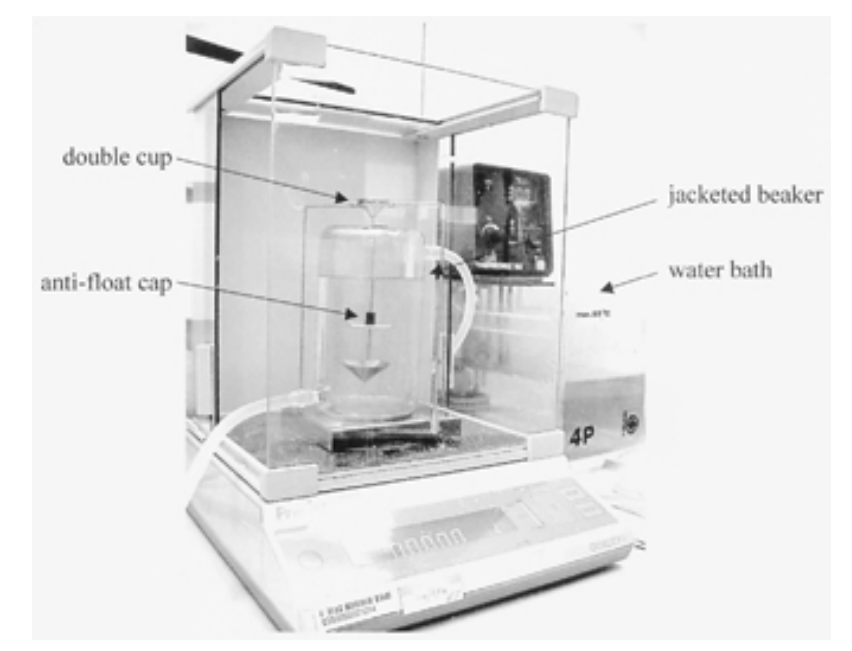

Fig. 1. Density measurement system, in which dough samples are weighed in air and immersed in xylene using a double-cup system. Temperature of the xylene is maintained by a jacketed beaker through which water recirculates from a temperature-controlled water bath. Antifloat cap allows measurement of low-density samples. 
system are illustrated in Fig. 1. Five replicate measurements were made for each dough.

The air content of doughs (the volume fraction of air per unit volume of aerated dough) mixed at atmospheric pressure $\left(\alpha_{30}\right)$ was calculated as

$$
\alpha_{30}=1-\frac{\rho_{30}}{\rho_{\mathrm{gf}}}
$$

where $\rho_{30}$ is the dough density at atmospheric pressure $(\approx 30$ " $\mathrm{Hg}$ abs) and $\rho_{\mathrm{gf}}$ is the gas-free dough density. The gas-free dough density was found by mixing doughs at different pressures (atmospheric and below) and extrapolating the measured densities back to zero absolute pressure, according to the procedure of Campbell et al (1993). The standard deviations of the estimates of $\rho_{\mathrm{gf}}$ and $\alpha_{30}$ were calculated according to Campbell et al (1993).

\section{Dynamic Dough Density During Proofing}

To monitor the dynamic dough density during proofing, a dough sample containing yeast was weighed in air, then placed in the bottom cup below an antifloat cap. The xylene was maintained at $40^{\circ} \mathrm{C}$, at which temperature the density of xylene is $0.85 \mathrm{~g} \mathrm{~cm}^{-3}$. The weight was recorded manually every $15 \mathrm{sec}$, starting $60 \mathrm{sec}$ after the end of mixing. When the dough density fell to below that of the xylene, the dough sample would float against the cap, giving a negative weight on the balance and thereby allowing densities $<0.85 \mathrm{~g} \mathrm{~cm}^{-3}$ to be measured. The changing dough density typically was monitored for 15-20 min. At the end of this period, the dough sample was removed from the xylene, allowed to dry, and reweighed in air to check that the weight had not changed significantly due to dissolution of any components into the xylene.

To test the effectiveness of the density monitoring procedure, dough samples were prepared from the weak flour and maintained in the xylene at $27,33,37$, and $43^{\circ} \mathrm{C}$, and the change in density followed. The effect of the surfactants was then evaluated, again using the weak flour, with DATEM and SSL added at 0, 0.4, and $0.7 \%$, flour weight basis.
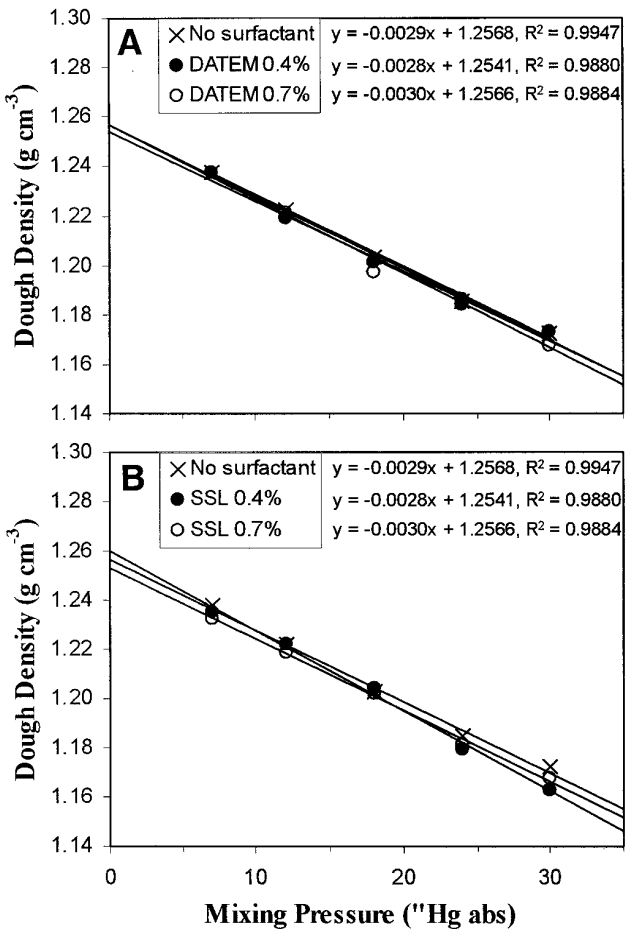

Fig. 2. Variation of dough density with mixing pressure for doughs made from strong flour with diacetyl tartrate esters of monoglyceride (DATEM) (A) and sodium stearoyl lactylate (SSL) (B) added at 0, 0.4, and 0.7\%, flour weight basis.

\section{Baked Loaf Preparation and Examination}

Baked loaves were prepared from doughs mixed from the strong flour at each of the three levels of surfactant. Two $250 \mathrm{-g}$ lumps of dough were obtained from each batch, molded by hand into a hemispherical shape, and placed into greased baking pans (136 $\mathrm{mm}$ in length, $74 \mathrm{~mm}$ wide at the base, $86 \mathrm{~mm}$ in height). The dough pieces were proofed at $40^{\circ} \mathrm{C}$ for $50 \mathrm{~min}$ in a $\mathrm{P} \& \mathrm{D}$ Incubator (Laboratory Supplies Ltd., UK), in which containers of water were placed to provide a moist environment. Proofing was timed from $10 \mathrm{~min}$ after the beginning of mixing. Proofed doughs were baked at $225^{\circ} \mathrm{C}$ for $25 \mathrm{~min}$ in a Simon rotary test baking oven (Robinson Milling Systems Ltd., UK). Baked loaves were cooled overnight and loaf volumes measured using rapeseed displacement.

\section{RESULTS AND DISCUSSION}

\section{Aeration and Gas-Free Dough Density}

The density versus mixing pressure for doughs mixed from the strong and weak flour is shown in Figs. 2 and 3, respectively, with different levels of either DATEM or SSL. Each data point is averaged from five measurements (error bars not shown because they were similar in size to the symbols plotted on the graph). In all cases, the change in density with mixing pressure is linear, confirming previous findings (Campbell et al 1993; Campbell and Shah 1999). However, the addition of surfactants appears to have no effect on either the gas-free dough density or the extent of aeration of the dough. The gas-free dough density is shown in Fig. 4A as a function of surfactant level for the two flours and two surfactants. The results for the weak flour are more variable than for the strong flour. However, there is no consistent trend in the effect of either surfactant for either flour, suggesting that surfactant has no effect on gas-free dough density. The gas-free density of the dough made from weak flour was larger than that of the strong flour, an average of $1.2720 \mathrm{~g} \mathrm{~cm}^{-3}$ compared with $1.2560 \mathrm{~g} \mathrm{~cm}^{-3}$, despite the same water levels in the two doughs. This also agrees with Campbell et al (1993).
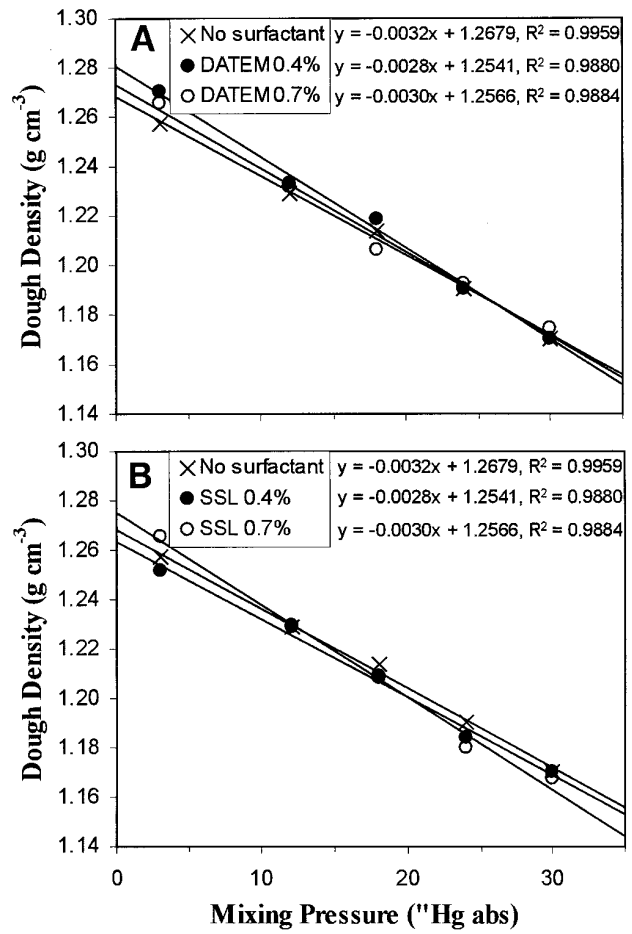

Fig. 3. Variation of dough density with mixing pressure for doughs made from weak flour with diacetyl tartrate esters of monoglyceride (DATEM) (A) and sodium stearoyl lactylate (SSL) (B) added at 0, 0.4, and $0.7 \%$, flour weight basis. 
Air content at atmospheric pressure as a function of surfactant level is shown in Fig. 4B for the two flours and two surfactants. Again, there is no consistent trend for either surfactant. The two surfactants gave effects opposite to each other and the effect of each was reversed for the two flours. This could indicate a complex and subtle interaction between flour type and surfactant, requiring further work to confirm. More probably, the results indicate that, in this system, the addition of surfactant appears not to affect aeration of the dough during mixing. This is supported by Junge et al (1981), who concluded that "surfactants do not alter the amount of air occluded during mixing" (although they did find that surfactants altered dough development times in a mixograph and hence the rate of air occlusion, as aeration depends on dough rheology).

The weak flour gave a larger air content (average $8.1 \%$ ) compared with that of the dough mixed from the strong flour (average $7.1 \%$ ). This is in agreement with the findings of Chamberlain et al (1970) and Campbell et al (1993) that the void fraction of air in a dough decreases with increasing flour strength.

Addition of surfactant does not appear to affect the total air content of doughs mixed in a Tweedy-type mixer. It may be, therefore, that surfactant also has no effect on the bubble size distribution created in the mixer. As noted above, both the total air content and the bubble size distribution are affected by the balance between entrainment and disentrainment of air during mixing, and it is unlikely that one would be affected and not the other. If smaller bubbles were produced by the addition of surfactant, independently of the overall air content, the increased surface area for mass transfer of $\mathrm{CO}_{2}$ into bubbles ought to affect the rate of growth of the dough piece. This gives another means to evaluate the effect of surfactants on aeration.
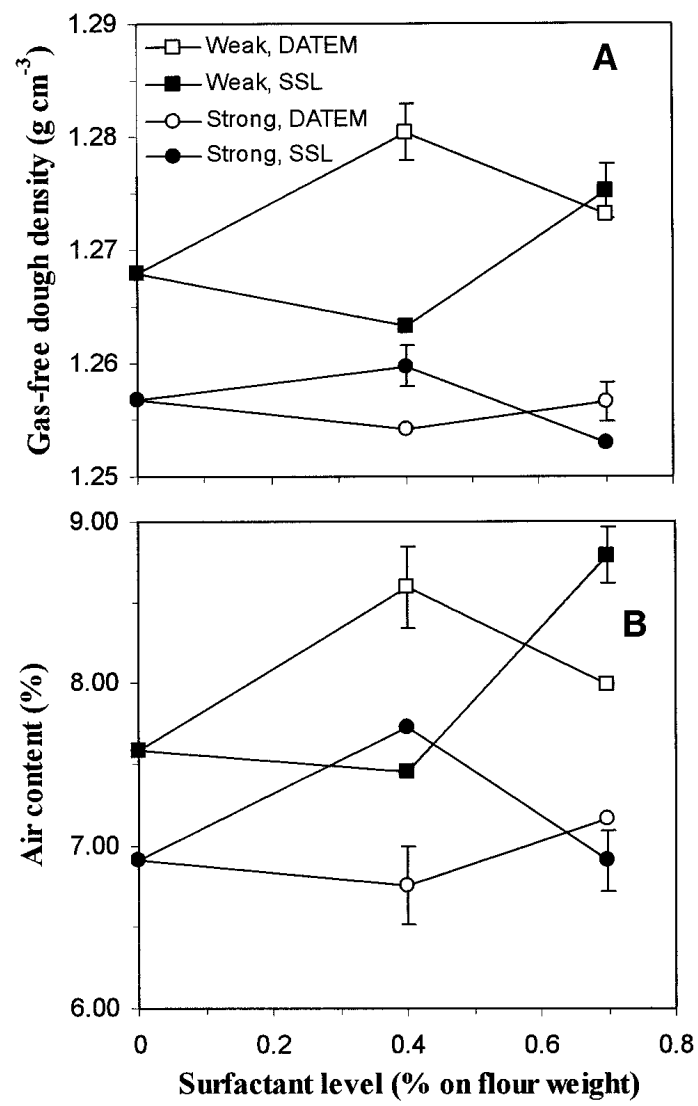

Fig. 4. Effect of surfactant level and type on aeration of doughs made with strong and weak flours when mixed at atmospheric pressure. A, effect on gas-free dough density. B, effect on air content. Error bars \pm 1 SD.
Effect of Surfactant Addition and Flour Type on Growth of the Dough Piece During Proofing

The growth of the dough piece was followed by monitoring the change in density with time. To test the effectiveness of this procedure, yeasted doughs were prepared from the strong flour, and allowed to proof at different temperatures in the xylene. The change in density of the dough piece with time for doughs held at different temperatures is shown in Fig. 5. Clearly, as temperature increased the dough piece grew more rapidly, demonstrating that this procedure can detect changes in the rate of gas production and retention.

The change in dough density for doughs prepared from the weak flour with each of the two surfactants at levels of $0,0.4$, and $0.7 \%$, flour weight basis, is shown in Fig. 6. For the DATEM, the data suggest that adding the surfactant caused the dough density to decrease more rapidly, indicating more rapid transfer of $\mathrm{CO}_{2}$ into bubbles. A similar but smaller effect is evident for the SSL.

These findings are consistent with more bubbles, and hence a higher surface area for mass transfer, in the doughs containing the surfactant. However, an alternative explanation is that the rate of mass transfer is increased because the surfactant, in decreasing the surface tension at the interfaces of bubbles, decreases the partial pressure of $\mathrm{CO}_{2}$ in the bubbles and, hence, increases the concentration driving force for mass transfer.

Resolving which, if either, of these explanations is correct requires a better understanding of the growth of bubbles during proofing. Mathematical models based on diffusive mass transfer theory, such as those presented by Shimiya and Yano $(1987,1988)$ and Shah et al $(1998,1999)$ are needed to model the growth of the entire population of bubbles. Such models require information about the initial bubble size distribution; the $\mathrm{CO}_{2}$ production rate, solubility, and diffusivity; and the bulk and surface rheology of the dough. Validation of such models is difficult. The method presented here, which allows the rate of growth of the dough piece to be quantified, will be useful in evaluating such models.

\section{Effect of Surfactant Addition and Flour Type on Baked Loaf Volume and Texture}

The effectiveness of the two surfactants at improving baked loaf volume and texture was checked for the strong flour. The baked loaf volume as a function of surfactant level for the two surfactants is shown in Fig. 7. Clearly, addition of $0.4 \%$ surfactant, flour weight basis, resulted in a dramatic improvement in loaf volume for both surfactants. Further addition of either surfactant showed little effect, and the difference in effectiveness of the DATEM and SSL was too small to be detected from a single trial with the loaf volume measurement system used.

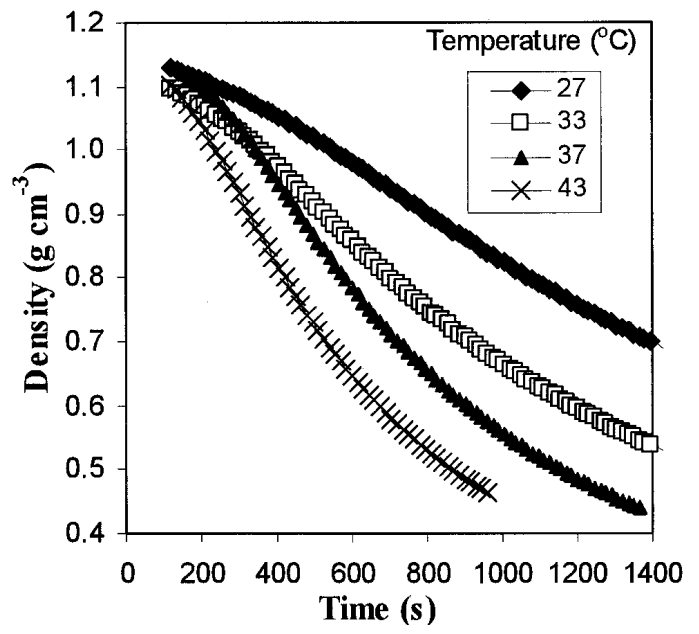

Fig. 5. Change in dough density with time during proofing of doughs at different temperatures. 

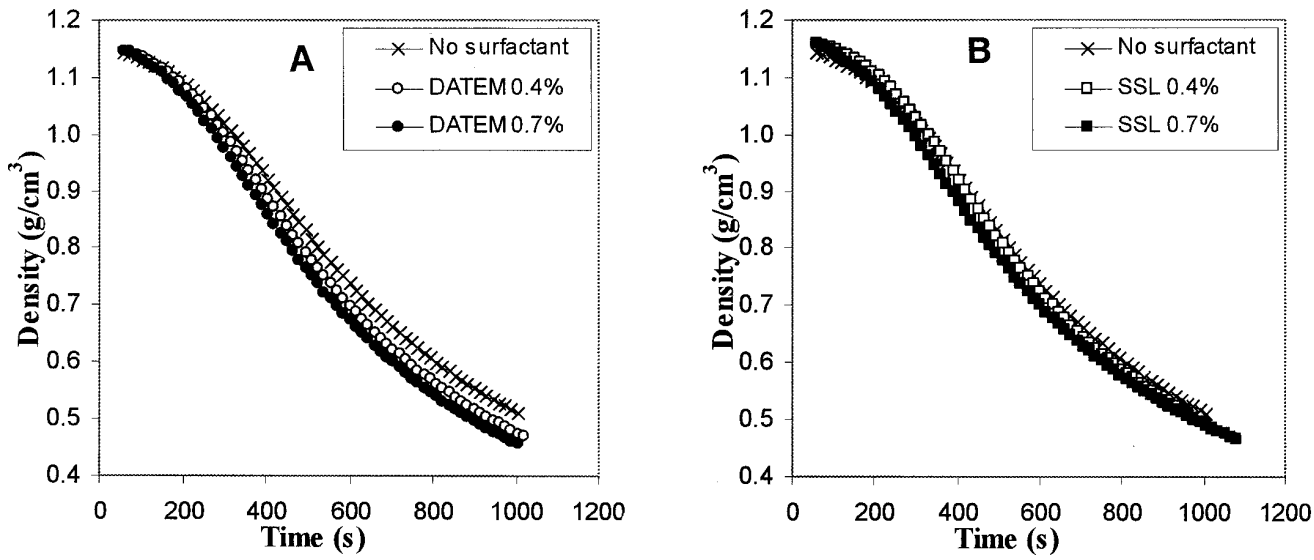

Fig. 6. Change in dough density with time during proofing of doughs prepared from weak flour with different levels of diacetyl tartrate esters of monoglyceride (DATEM) (A) and sodium stearoyl lactylate (SSL) (B).

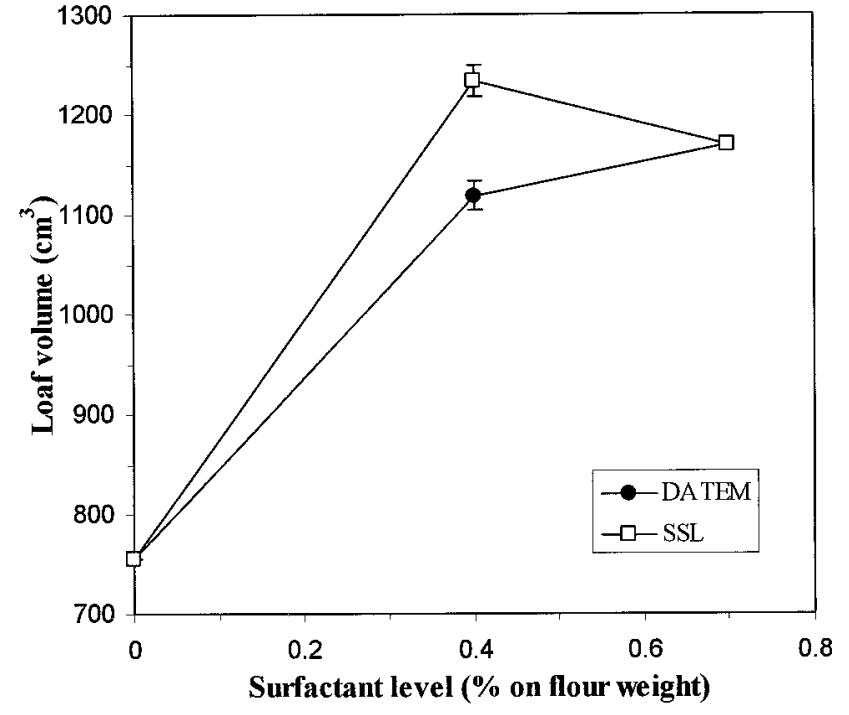

Fig. 7. Effect of surfactant addition on volume of loaves prepared from strong flour. Data from duplicate measurements. Error bars \pm 1 SD.

\section{CONCLUSIONS}

A new system has been described for the rapid and accurate measurement of dough density, for the assessment of aeration of bread doughs. The system involves weighing small dough samples in air and immersed in xylene. The use of xylene allows lower density doughs to be measured and avoids dissolution of the dough. The system can be used to measure the density of doughs ex-mixer or to follow the change in dough density during proofing. Doughs of very low density can be measured by using an antifloat cap and recording the upward buoyancy force of the dough and, hence, its density. The ability to quantify the change in dough density and, hence, gas production during proofing opens the way to a range of useful investigations.

The system was used to study the effect of flour strength and surfactant type and level on aeration of the dough during mixing and subsequent growth of the dough piece during proofing. Weak flour had a higher gas-free dough density and gave greater aeration than strong flour, in agreement with previous findings. The addition of surfactants DATEM or SSL at 0.4 and $0.7 \%$, flour weight basis, gave greatly improved loaf volumes but had no distinguishable effect on gas-free dough density or the air content of doughs before proofing. The subsequent growth of dough pieces during proofing seemed to be enhanced by the addition of surfactant. This could be due to enhanced bubble breakup during mixing, giving greater surface area for mass transfer, or to the decreased partial pressure of $\mathrm{CO}_{2}$ in the bubbles enhancing the mass transfer driving force. Mathematical modeling of bubble growth during proofing is needed to resolve these alternative explanations. The method presented here for following the growth of a dough piece during proofing will help in validating such models.

\section{ACKNOWLEDGMENTS}

We thank Rank Hovis Mills, Manchester, UK, for providing flour; Arkady Craigmillar, Manchester, UK for providing improvers and surfactants; and the Satake Corporation of Japan for support in the activities of the Satake Centre for Grain Process Engineering.

\section{LITERATURE CITED}

Armero, E., and Collar, C. 1996a. Antistaling additive effects on fresh wheat bread quality. Food Sci. Technol. Int. 2:323-333.

Armero, E., and Collar, C. 1996b. Antistaling additives, flour type and sourdough process effects on functionality of wheat doughs. J. Food Sci. 2:299-303.

Baker, J. C., and Mize, M. D. 1946. Gas occlusion during dough mixing. Cereal Chem. 23:39-51.

Bloksma, A. H., and Bushuk, W. 1988. Rheology and chemistry of dough. Pages 131-217 in: Wheat: Chemistry and Technology. Vol. II. Y Pomeranz, ed. Am. Assoc. Cereal Chem.: St. Paul, MN.

Bruinsma, B. L., and Finney, K. F. 1984. Various oils, surfactants, and their blends as replacements for shortening in breadmaking. Cereal Chem. 61:279-281.

Campbell, G. M., Rielly, C. D., Fryer, P. J., and Sadd, P. A. 1991. The measurement of bubble size distributions in an opaque food fluid. Trans. IChemE, Part C, Food Bioprod. Proc. 69:67-76.

Campbell, G. M., Rielly, C. D., Fryer, P. J., and Sadd, P. A. 1993. Measurement and interpretation of dough densities. Cereal Chem. 70:517-521.

Campbell, G. M., Rielly, C. D., Fryer, P. J., and Sadd P. A. 1999. Reconstruction of bubble size distributions from slices. Pages 207-220 in: Bubbles in Food. G. M. Campbell, C. Webb, S. S. Pandiella, and K. Niranjan, eds. Am. Assoc. Cereal Chem.: St. Paul, MN.

Campbell, G. M., and Shah, P. 1999. Entrainment and disentrainment of air during bread dough mixing, and their effect on scale-up of dough mixers. Pages 11-20 in: Bubbles in Food. G. M. Campbell, C. Webb, S. S. Pandiella, and K. Niranjan, eds. Am. Assoc. Cereal Chem.: St. Paul, MN.

Cauvain, S. P., Whitworth, M. B., and Alava, J. M. 1999. The evolution of bubble structure in bread doughs and its effect on bread structure. Pages 85-88 in: Bubbles in Food. G. M. Campbell, C. Webb, S. S. Pandiella, and K. Niranjan, eds. Am. Assoc. Cereal Chem.: St. Paul, MN.

Chamberlain, N., Collins, T. H., and Elton, G. A. H. 1962. The Chorleywood Bread Process. Baker's Dig. 36:52-53.

Chamberlain, N., Collins, T. N., and Redman, B. I. 1970. The Chorleywood Bread Process: Effect of reduced pressure during mixing. FMBRA Report 40. Flour Millers and Bakers Research Association: Chorleywood, UK. 
Collar, C., Armero, E., and Martinez, J. 1998. Lipid binding of formula bread doughs-Relationships with dough and bread technological performance. Food Res. Technol. 207:110-121.

Gan, Z., Ellis, P. R., and Schofield, J. D. 1995. Gas cell stabilization and gas retention in wheat bread dough. J. Cereal Sci. 21:215-230.

Hayman, D., Hoseney, R. C., and Faubion, J. M. 1998. Bread crumb grain development during baking. Cereal Chem. 75:577-580.

He, H., and Hoseney, R. C. 1991. Differences in gas retention, protein solubility and rheological properties between flours of different baking quality. Cereal Chem. 68:526-530.

Inoue, Y., Sapirstein, H. D., and Bushuk, W. 1995. Studies on frozen doughs. IV. Effect of shortening systems on baking and rheological properties. Cereal Chem. 72:221-226.

Junge, R. C., and Hoseney, R. C. 1981. A mechanism by which shortening and certain surfactants improve loaf volume in bread. Cereal Chem. 58:408-412.

Junge, R. C., Hoseney, R. C., and Varriano-Marston, E. 1981. Effect of surfactants on air incorporation of dough and crumb grain of bread. Cereal Chem. 58:338-342.

Keetels, C. J. A. M., van Vliet, T., Jurgens, A., and Waslstra, P. 1996. Effects of lipid surfactants on the structure and mechanics of concentrated starch gels and starch bread. J. Cereal Sci. 24:33-45.

Kenny, S., Wehrle, K., Dennehy, T., and Arendt, E. K. 1999. Correlations between empirical and fundamental rheology measurements and baking performance of frozen bread dough. Cereal Chem. 76:421-425.

Knightly, W. H., 1981. Shortening systems: Fats, oils and surface active agents-Present and future. Cereal Chem. 58:171-174.

Knightly, W. H., 1988. Surfactants in baked foods: Current practice and future trends. Cereal Foods World 33:405-409.

Kohler, P., and Grosch, W. 1999. Study of the effect of DATEM. I. Influence of fatty acid chain length on rheology and baking. J. Agric. Food Chem. 47:1863-1869.

Krog, N. 1981. Theoretical aspects of surfactants in relation to their use in breadmaking. Cereal Chem. 58:158-164.

Lindsay, R. C. 1996. Food additives. Pages 767-823 in: Food Chemistry, 3rd edition. O. R. Fennema, ed. Marcel Dekker: New York.

Moore, W. R., and Hoseney, R. C. 1986. Influence of shortening and surfactants on retention of carbon dioxide in bread doughs. Cereal Chem. 63:67-70.

Roach, R. R., and Hoseney, R. C. 1995. Effect of certain surfactants on the starch in bread. Cereal Chem. 72:578-582.

Shah, P., Campbell, G. M., Dale, C., and Rudder, A. 1999. Modeling bubble growth during proofing of bread dough: Predicting the output from the Chopin Rheofermentometer. Pages 95-106 in: Bubbles in Food. G. M. Campbell, C. Webb, S. S. Pandiella, and K. Niranjan, eds. Am. Assoc. Cereal Chem.: St. Paul, MN.

Shah, P., Campbell, G. M., McKee, S. L., and Rielly, C. D. 1998. Proving of bread dough: Modeling the growth of individual bubbles. Trans. IChemE Part C. Food Bioprod. Proc. 76:73-79.

Shimiya, Y., and Yano, T. 1987. Diffusion-controlled shrinkage and growth of an air bubble entrained in water and in wheat flour particles. Agric. Biol. Chem. 51:1935-1940.

Shimiya, Y., and Yano, T. 1988. Rate of shrinkage and growth of air bubbles entrained in wheat flour dough. Agric. Biol. Chem. 52:28792883.

Stampfli, L., Nersten, B., and Molteberg, E. L. 1996. Effects of emulsifiers on farinograph and extensigraph measurements. Food Chem. 57:523530 .

Stauffer, C. E. 1999. Emulsifiers. Am. Assoc. Cereal Chem.: St. Paul, MN.

Tsen, C. C., and Weber, J. 1981. Dough properties and proof times of yeasted doughs affected by surfactants. Cereal Chem. 58:180-181.

Tu C. C., and Tsen C. C. 1978. Effects of mixing and surfactants on microscopic structure of wheat glutenin. Cereal Chem. 55:87-95.

Whitworth, M. B., and Alava, J. M. 1999. The imaging and measurement of bubbles in bread doughs. Pages 221-231 in: Bubbles in Food. G. M. Campbell, C. Webb, S. S. Pandiella, and K. Niranjan, eds. Am. Assoc. Cereal Chem.: St. Paul, MN.

Xu, A., Chung, O. K., and Ponte, J. G. 1992. Bread crumb amylograph studies. I. Effects of storage time, shortening, flour lipids and surfactants. Cereal Chem. 69:495-501.

[Received May 30, 2000. Accepted January 22, 2001.] 